\title{
"The Awful Rowing toward God": Interpretation of Religious Experiences by Individuals with Bipolar Disorder
}

\author{
Eva Ouwehand ${ }^{1,2}$ (D) T. Hetty Zock ${ }^{2} \cdot$ J. K. Hanneke Muthert ${ }^{2} \cdot$ Hennie Boeije $^{3} \cdot$ \\ Arjan W. Braam ${ }^{4,5}$
}

Published online: 11 May 2019

(C) The Author(s) 2019

\begin{abstract}
Limited research has been conducted on the religious experiences of people with bipolar disorder (BD). Qualitative research indicates that the disentanglement of pathology and genuine religiosity is an important issue for persons with $\mathrm{BD}$ and that some patients experience discrepancy between the explanatory models of mental health care professionals and religious leaders. The current study explores the ways patients with BD interpret religious experiences they have had during illness episodes, how this interpretation changes over an individual's lifetime, and the expectations of treatment that persons with $\mathrm{BD}$ have regarding these religious experiences. Semi-structured interviews with 34 stable BD patients were conducted by a hospital chaplain and a psychiatrist trainee. The method of analysis was interpretative phenomenological analysis. For many participants, a religious quest originated after a religious experience during mania, and then a variety of medical and religious sources supported the interpretation process. Most participants endorsed mixed medical and religious explanations for their experiences and tried to distinguish between spiritual and pathological features. The interpretation process changed over time, influenced by religious affiliation and views, mood swings and the course of BD, and communication with others about the experiences. Discourse about the experiences was often problematic within treatment; a majority expressed the need for recognition of the spiritual value of the experiences, together with a critical sounding board for reflecting on their meaning and the influence of BD. More attention could be paid to the subject in treatment, and the expertise of hospital chaplains could contribute to this.
\end{abstract}

Keywords Explanatory models $\cdot$ Interpretation $\cdot$ Religious experiences $\cdot$ Bipolar disorder

Eva Ouwehand

e.ouwehand@altrecht.nl

Extended author information available on the last page of the article 


\section{Introduction}

The Awful Rowing toward God is the title of a poetry collection (1999) by Ann Sexton (19281974), written one year before her suicide. Sexton was diagnosed with bipolar disorder (BD) (previously known as manic-depressive disorder) in 1954. Her poems in this collection reflect both her severe suffering and her fierce religious longing, coupled with her profound questioning of the destiny of (wo) mankind and the meaning of life. The current study, conducted within the context of hospital chaplaincy in mental health care, concerns the interpretation of religious and spiritual experiences of persons with BD. In the sparse patient-centered literature on BD in relation to religiosity, the question of whether such experiences are a sign of hyperreligiosity or reflect genuine spirituality emerges as an important theme for patients (Michalak et al. 2006; Ouwehand et al. 2014). This qualitative study explores how individuals value and interpret self-reported religious and spiritual experiences that occur during episodes of illness.

\section{Bipolar disorder}

Bipolar disorder is a mental illness that occurs in about $2 \%$ of the Dutch population (Regeer et al. 2004). Owing to the cyclic nature of $\mathrm{BD}$, manic and depressive periods recur, alternating with periods of stability in between. Characteristic of (hypo)mania is a continually elevated, expansive, or irritable mood accompanied by increased energy or activity, a decreased need for sleep, and overestimation of oneself (Kupka and Nolen 2009). In hypomania, distinctive for bipolar II disorder (BD II), psychotic features are absent and patients are less impaired in daily functioning than in bipolar I disorder (BD I), which has mania as its distinctive feature. Although (hypo) mania is more prominent in the public's perception of the illness, depressive episodes do in fact occur more often and are of longer duration than (hypo) manic episodes (Kupka and Nolen 2009). The depressive phase is accompanied by loss of interest in life and imbalanced appetite, sleep, and psychomotor activity. Together with a decrease in energy, concentration, and decisiveness comes the onset of feelings of guilt and worthlessness; preoccupation with death may be accompanied by suicidal plans or attempts. Manic and depressive symptoms can occur simultaneously (mixed episodes), and much individual variation in the course and manifestation of the illness is present (Kupka and Nolen 2009).

\section{Religious experience and bipolar disorder}

Very few studies concerning the religious experiences of people with BD are available (Gallemore Jr et al. 1969; Kroll and Sheehan 1989; Ouwehand et al. 2018). Studies of the interpretation of religious experiences of persons with a bipolar diagnosis are not known to the authors; this is the focus of the current study. Religious experiences can occur when people are stable. However, when they occur during illness episodes, these experiences may still be viewed as religious by patients. This interpretation does not necessarily coincide with the medical model because psychiatric research usually only focuses on psychopathology with religious content. According to studies carried out in the United States, it appears that the prevalence of delusions with a religious content within manic episodes can be estimated at 1533\% (Appelbaum et al. 1999; Koenig 2007) and at 38\% in India (Grover et al. 2016). For the Netherlands, where the current study was conducted, no figures are available. Two studies address religious experience in BD, i.e., conversion/salvation experiences (Gallemore Jr et al. 
1969) and various experiences with an evangelical/charismatic focus (Kroll and Sheehan 1989). Both studies were conducted within a predominantly Christian context.

The present religious landscape in the Netherlands, however, is much more secularized and pluralistic than the context of the aforementioned studies. Institutional affiliation to any of the world religious traditions is estimated ay $28-32 \%$ in national surveys (Bernts and Berghuijs 2016; Kronjee and Lampert 2006). In recent surveys in the sociology of religion, the selfdefinition of people as religious or as spiritual is increasingly measured. This leads to a four-fold typology of persons who consider themselves as 'only religious', 'only spiritual', 'religious and spiritual', and 'religious nor spiritual' (Bernts and Berghuijs 2016; Possamai 2005; Streib and Hood 2016). Unlike in the United States, where a majority of people view themselves as both religious and spiritual, the self-designation as 'only religious' or as 'only spiritual' are becoming diverging life orientations in the Netherlands, according to social scientists (Berghuijs et al. 2013). Furthermore, a growing percentage of the population (23\%) is committed to more than one religious tradition, resulting in what Berghuijs (2017) characterizes as 'hybrid religiosity.' Although Dutch sociological surveys have estimated the prevalence of some types of religious experience (the experience of the divine presence, mystical experience, and experiences of transcendence without referring to the divine) in the general population (Berghuijs 2016, 2017; Bernts and Berghuijs 2016; De Hart 2011), no accepted classification of religious experience in the pluralistic situation of modern Western societies is available.

The theoretical basis for the current study is Streib and Hood's (2016) cross-cultural study of modern 'spirituality.' Following Troeltsch's (1923) typology of religion in 'church,' 'sect,' and 'mysticism,' they view this last 'ideal type' as the noninstitutionalized forms of religion that have privatized, personal religious experience as their main focus. Streib and Hood reactualized Troeltsch's typology for the contemporary religious landscape in Western secularized societies. The tendency toward experience-oriented religion is visible not only within the churches, in the growing influence of evangelicalism, but also in various 'alternative,' 'new,' or 'holistic' spiritualities (De Hart 2011; Possamai 2005; Van Harskamp 2000). In this article, we use the etic term 'new spirituality' (De Hart 2011) to describe the religious orientation of participants in the study, bearing in mind that from an emic perspective individuals may attribute different meanings to the concepts 'religion' and 'spirituality.' The point of departure of the study is to describe the interpretation of religious experience within the participants' own frame of reference.

Hitherto, there has been little research done into the kinds of religious experience that can occur in BD and the influence such experiences have on persons with this diagnosis. A qualitative study (Ouwehand et al. 2018) indicated different types of self-reported religious and spiritual experiences in $\mathrm{BD}$, predominantly occurring during mania. Most mentioned were experiences of the presence of a transcendental reality, either divine or more this-worldly, of unity, of vocation/mission, or of meaningful synchronicity. Less mentioned were the various other religious or spiritual experiences of a paranormal or supernatural kind such as apparitions and voices, symbolic images or visions, and out-of-body experiences. Negative religious experiences were present as well.

\section{Interpretation of religious experience in BD}

An important issue for clinical practice is the relation between psychiatric categories such as 'psychosis,' 'hallucinations' and 'delusions,' and phenomenological patient-reported descriptions and interpretations of their religious experiences. Medical anthropologists have consistently 
argued that conflicting 'explanatory models' that patients and doctors apply to illness may impair treatment (Helman 2001; Kleinman 1988, 1991). Mitchell and Romans (2003) and Stroppa and Moreira-Almeida (2013) empirically confirmed this observation for patients with BD. The concept of the explanatory model pertains to the process by which illness is patterned, interpreted, and (medically) treated within a culture. In addition to professional and scientific medical explanatory models, Helman (2001) distinguishes between lay explanatory models, i.e., the ways in which the individuals in their social context explain the illness, and folk explanatory models, referring to secular and sacred alternative healing within a society. In medical anthropology, explanatory models in small-scale societies and migrant groups in Western societies are usually studied. In the fifth edition of the DSM the assessment of personal explanatory models for illness experiences is included in the 'Cultural Formulation Interview' (DSM-5, American Psychiatric Association 2013). However, the concept of explanatory models is useful for the current study as well and functions as a 'sensitizing concept' (Boeije 2010). It clarifies the interaction between the different and sometimes conflicting explanations for religious experiences related to BD in persons with this diagnosis.

\section{Narrative}

'Narrative' is another theoretical concept underlying the current study. Ganzevoort and Visser (2009) take it as the basis for their model of pastoral care. The concept evolved from the hermeneutical tradition of Hans-Georg Gadamer and Paul Ricoeur and points to the inherently narrative character of identity. In the stream of happenings and experiences in people's lives, individuals construct stories that organize their sense of self and memory (Bruner 1991; Cook 2016). These stories create coherence in the tension between historical and familial predisposition and openness to an indefinite future. Narrative approaches imply that humans have a dynamic, open identity, which cannot be fixed during their lifetime and which has an inherently dialogical character (Ganzevoort and Visser 2009; Zock 2013). Cook (2016) points to the additional challenge for individuals with a psychiatric diagnosis with regard to biographical reflexivity. An illness narrative is a particular kind of life story, related to and partly overlapping with other narratives such as spiritual autobiographies or narratives of surviving trauma. People suffering from mental illnesses that impede reflexive capacities because of mood disturbance or lack of cognitive clarity may have problems in constructing narratives that foster recovery, according to Cook. In the case of BD, it can be expected that mood swings will influence a person's sense of self and the way individuals interpret religious experiences that are related to mood episodes.

\section{Aim and research questions}

From the literature, it is evident that although religious experience is an important issue for individuals with $\mathrm{BD}$, it has been neither well examined nor well understood within the context of psychiatry. It is also a relevant issue to be discussed during treatment in which different explanatory models are in use. Therefore, we formulated the following research questions:

1) During stable periods, how do people with a diagnosis of BD retrospectively interpret the religious experiences that occurred during their episodes of illness?

2) Do these interpretations change over the years?

3) What do patients with $\mathrm{BD}$ expect of treatment with regard to their religious experiences? 
In answering these questions, we seek to contribute to the identification of the discrepancies between different explanatory models in clinical practice. In such a way, we hope to improve treatment on this point. As this is a multidisciplinary study, some theological reflections on religious experience in the context of mental illness will be presented as well. In this time of increasing community-based mental health care, possible directions for the improvement of pastoral care in ecclesiastical life will also be discussed.

\section{Methods}

\section{Research design}

The current study had a qualitative design, an appropriate approach for exploring a hitherto sparsely examined subject (Boeije 2010). Interpretative phenomenological analysis was used for examining the data (Biggerstaff and Thompson 2008; Smith and Osborn 2008). This approach is similar to the hermeneutic phenomenology that Swinton and Mowat (2006) applied in their study of depression and spirituality. Phenomenology attempts to describe phenomena comprehensively and in great detail without initially imposing the theoretical presumptions of the researcher on the analyzing process; the term 'bracketing' is used for this (Biggerstaf and Thompson 2008). As in all qualitative research, participants' own understanding of a phenomenon (interpretations of religious experience in the context of BD) is the point of departure. At the same time, all qualitative research presumes that humans can only make sense of the world by implicit and explicit interpretative processes; human beings are inevitably hermeneutical beings (Swinton and Mowat 2006). The researcher's preunderstanding is therefore always present. The fact that the researcher in this case (the first author) is more aligned with discourse in the discipline of religious studies than in the psychology of religion has influenced, for example, the choice of using anthropological and sociological theory in the analyzing process more than, for example, psychodynamic theory. Furthermore, the researcher's experience as a hospital chaplain with a liberal Protestant background has affected her theological reflection on the results.

Participants in the study were interviewed when they were stable. Reflection on the meaning of experiences of illness episodes and their impact on the lives of participants can be important for recovery (Leamy et al. 2011). However, because the capacity to reflect is usually seriously impaired during full-blown mania or depression, the interviews took place after recovery from an episode.

\section{Data collection}

The data collected were comprised of interviews and, additionally, of written testimonials by five of the participants sent to the researcher after the interview. Although the intention was to include participants with differences in age, religious and educational background, and duration of the illness, participants with a fundamentalist or pietistic Christian background as well as members of religious and ethnic minorities were difficult to recruit. Recently diagnosed patients were underrepresented in the study as well. When theoretical saturation in the available groups was reached, recruitment ended. The participants, 34 in total, were first enlisted via two mental health institutions - Altrecht and Eleos (17 participants) — and via a peer support project of a patient organization (www.ervaringrijk.nl, 8 participants). Potential 
participants could also apply in response to a blog (Ouwehand 2015) on an interactive website for professionals and people with psychotic disorders (38 applications, many with an affiliation to new spirituality; the first nine stable applicants were included).

To become acquainted with the field of research, the first author attended several conferences and meetings of the patient's organization concerning 'psychosis and spiritual crisis' and 'BD and spirituality' between 2013 and 2017. Relevant websites and recovery stories referred to by participants in the study were examined (www.psychosenet.nl, www.ervaringrijk.nl, www.vmdb.nl, www.nieuwetijdskinderen.nl, www.petraetcetera.nl, www.pamela-kribbe.nl, www.bipolairanders.nl). The researcher established informal contact with two persons in the patient organization, and they gave advice several times during the initial phase of the study. Observations and memos functioned as background information to develop insight in the field. This material was predominantly influenced by new spirituality. No other network or organization within institutionalized religion with a focus on BD was known to the researcher.

\section{Interview procedure}

The interviews were semi-structured (see appendix for the list of topics). In the current study, the topics presented are 'interpretation of the religious or spiritual experiences occurring in illness episodes' and 'treatment experiences and expectations.' A previous publication addressed the phenomenological description of religious or spiritual experiences during mania and depression and in stable periods (Ouwehand et al. 2018). The interviews lasted approximately two hours and were carried out by a hospital chaplain (the first author) and a psychiatrist or trainee psychiatrist. Assessment of patient stability was done using the Altman Self-Rating Mania Scale (Altman et al. 1997) and the Quick Inventory of Depressive Symptomatology-Self-Report (Rush et al. 2003). The psychiatrist employed the Clinical Global Impressions Scale for use in bipolar illness (Spearing et al. 1997) for an independent rating.

\section{Data analysis}

The interviews were audiotaped, transcribed verbatim, and sent to the participants for possible correction. The analysis of the interview texts was done using NVivo10. The hospital chaplain and the resident psychiatrist, who were co-interviewers in the first ten interviews, coded interview 1 independently. Interviews 2 through 6 were analyzed by either one or the other. Differences in the professional backgrounds of the interviewers (theological and medical) resulted in an exchange concerning ways of interpreting the data and a clarification of professional presuppositions. During this process, a common code list was developed and adjusted during several discussion sessions. In this way, the participants' expressions and attribution of meaning as well as valuable diagnostic information could be coded. Interviews 7 through 10 were analyzed by the first author, who discussed the results with the co-interviewer. The next step in the research process was to extend the sample to 34 participants in total; these participants had more diversity in religious background, in demographic characteristics, and in duration of the illness (recently diagnosed vs. long-established BD). The code tree of the first ten interviews served as a basis and was adapted for the subsequent coding and analyzing process, wherein these 10 interviews were reanalyzed. A summary of all interviews was prepared that contained the main subjects of the interviews. The interviews comprised the main body of analysis. The written testimonials of participants were also used in the process of analysis if they clarified themes in the individual interviews. 


\section{Ethics}

Participants were informed about the aims and procedure of the study and were, on request, provided with the list of topics in advance. All participants signed a consent form before the interview. In a few cases, the participant knew one of the interviewers from a former counseling or assessment contact. The issue was discussed with the participants concerned and in one case resulted in the replacement of the co-interviewer before the interview. The study was approved by the Regional Medical Ethical Committee of the University Medical Center Groningen (METc2014.475) and the Scientific Committee of Altrecht Mental Health Care (2015-05/oz15012).

\section{Results}

\section{Sample characteristics}

The sample characteristics are summarized in Table 1. Most participants had a Christian background; six participants had no religious background, and three had been raised as Muslims. Religious affiliation changed during the course of most participants' lives. General sociological tendencies toward new spirituality, hybrid religiosity, and the increasing influence of evangelicalism were reflected in the sample. The affinity with religiosity was very high; only one person had no religious affiliation at the time of the interview. Thirteen participants had had some education in religious studies, theology, or philosophy (10) and/or had been trained in or had taken courses in new spirituality (5) at different educational levels, mostly in addition to other professional education. Most participants took medication and had regular contact with a general practitioner or mental health care professional.

Searching for meaning or being on a 'religious quest' was an important theme in many of the interviews. The theme referred to 'normal' psychological development with periods of more intense searching, which was explored in the topic 'religious roots and development' in the interviews. 'Religious quest' also referred to an intense searching for the meaning of the religious experiences that had occurred, especially during manic episodes. Pertaining to this last process, the intertwinement of genuine religious experiences and psychopathology was present in many of the interviews. Medical and religious terminology and interpretations were used side by side. This dual character of the experiences became clear, on the one hand, through the religious meaning participants ascribed to the experiences and, on the other hand, through their evaluation of certain features of the same experiences as influenced by BD. In the following sections, the three themes of 'religious quest,' 'spiritual growth,' and 'influence of BD' are presented. After that, exclusively spiritual and exclusively medical explanations for religious experiences_ — advocated by only a few participants_-will be addressed.

\section{Religious quest}

The theme 'religious quest' refers to two processes in the interviews. On the one hand, searching for meaning and a change in attitude toward religious traditions occurred during certain key moments or stages in a person's life, for example, in adolescence or as a consequence of a stressful life event. In this respect, the quest was part of 'normal' psychological development. To give an example, 16 participants were engaged in some form of new spirituality at the time of the interview, whereas only 
Table 1 Sample characteristics $N=34$

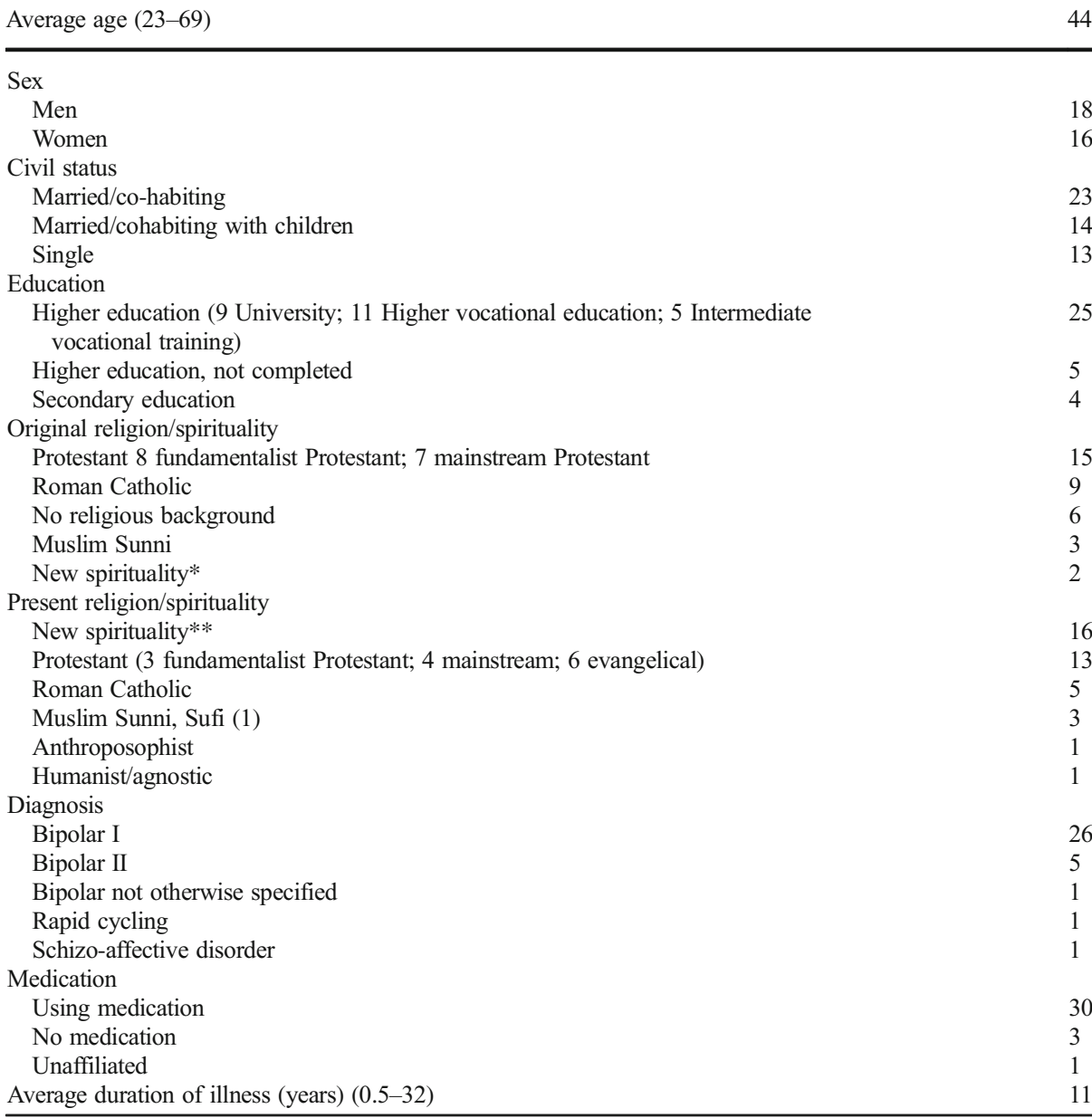

*One person mentioned this together with a Christian affiliation

**Five persons mentioned this together with a Roman Catholic (3) or Protestant (2) affiliation

two had been raised within this orientation. On the other hand, several participants had initiated a religious quest as a direct consequence of religious experiences occurring during mania. For example, this was the case for six participants who did not come from religious homes and had had no religious affiliation at the time of their first mania. In about one-third of the interviews, a religious or spiritual quest and the onset of a (hypo)manic episode seemed to be intertwined. The exact influence of one or the other was not always traceable in stories covering long periods of time. Moreover, the diagnosis of BD was usually determined only years after the first symptoms; the religious quest phenomenon and developing mania were possibly intertwined before the moment of diagnosis. The religious quest as a consequence of experiences during mania could at times take intense forms. Participants mentioned spiritual literature and the internet as sources of information, such as the teachings of Eckhart Tolle; they attended conferences, workshops, and personality training courses such as Crazy Wise, New Wine, Landmark, Psycho-Synthesis, or meetings of the 
BD patient organization; they consulted mental health professionals, clergy, or alternative healers to make sense of their experiences. The interviews represented a certain moment in time in a dynamic process taking place over years of searching and interpreting their experiences.

\section{Spiritual growth}

'Spiritual growth' or 'deepening faith' was a theme in 21 of the interviews and was described either as a moment of transformation, referred to by terms such as "a major clean-up," "a breakthrough," or an experience of "divine intervention," or as a more gradual process, referred to by process-based terms such as "a process of the deepening of faith" or "becoming richer through the illness." 'Spiritual growth' was related to four subthemes that were often interrelated: 'meaningful coherence,' referring to the feeling of meaningfulness, coherence, and purpose in life; 'insight' into the nature of reality or of oneself; 'overcoming trauma,' and 'perceived influence of the experiences.'

Meaningful coherence Many participants had experienced a feeling of coherence, of a meaningful connectedness during mania. This was described as a mystical experience of unity and, in the interpretation of apparently coincidental events, as having a cause and purpose or message. Although some participants mentioned that the feeling of significance could be exaggerated in mania, several others viewed this condition of connectedness, coherence, and intentionality as an inherent aspect of their spirituality; they felt things do not happen in vain and are often a sign of another, divine reality.

For a few participants, this feeling of purpose in their life was also pertinent to the fact that they had BD. In their eyes, their illness was predestined by God or a higher power or was a result of karma, "a grace" as well as a "challenge" (P31).

Insights Almost a third of the participants pointed out that their views on the nature of reality and the destiny of human beings had changed owing to their experiences. This theme refers to a deeper understanding of the human condition. Again, this was described by some as a sudden insight, directly related to their experiences, in existential themes such as "good and evil" (P20), "the nature of time" (P8), or "man's destiny" (P29). The experiences were taken as evidence that "there is more than you can see, that God is real" (P7) or that "an energy is pervading everyone" (P28). Profound changes in one's philosophy of life or in one's perception of oneself could evolve from the experiences. P25 remarked: "I am not the same person anymore. When your mind is expanded like this, there is no way back" (female, no religious education, new spirituality).

For others, insight had grown gradually and was described as a process of change, which was related to the theme 'perceived lasting influence.' Very few participants reported negative experiences, but when they did so, even these could be evaluated as contributing to insight in retrospect. Two participants referred to negative and frightening visions of evil during mania, which they evaluated afterward as strong incentives to change and recovery (P5, P29). This might be due to their Roman Catholic/Caribbean background, in which the presence of evil or the devil was assumed. P5 reported that such experiences had encouraged her to reflect more profoundly on the meaning of good and evil in general and in her personal life in particular.

Overcoming trauma Several participants saw a clear connection between their experiences during illness and overcoming the burdens of their past, intense life events, or trauma. Seven of 
them had already been involved in psychotherapy, in intense personality training, or in alternative therapy when mania, accompanied by religious experiences, evolved. They perceived their religious experience during mania as a "major clean-up" (P28) or "sweeping away the last filth" (P2) through which they coped with their past or with the burden of a former life. P5, a Roman Catholic woman with an interest in new spirituality, reported that listening to the content of psychosis was necessary for spiritual growth. She felt that if you rejected the content, the next psychosis was fed by this unfinished business. Several participants stressed the existential nature of the content of psychosis as it referred to important life themes such as good and evil, the intrinsic connectedness of all beings, or one's 'true' self.

Perceived lasting influence of the experiences In many interviews, participants reflected on the consequences of the process of change, either initiated by the religious experiences or by the therapeutic process of dealing with one's past, of which the experiences were an inherent part. The category 'perceived lasting influence' is an aggregation of various consequences, different in character, all mentioned by only a few participants. For some, this process of change had led to another attitude in life, which was described in terms of growing selfacceptance, trust, and life orientation. It could pertain to acceptance of BD and illness management as well: "taking due account of myself and of the illness" (P28). Concrete changes in life conditions such as a new job, relationship, or house were mentioned as well, although it did not always become clear what the cause of these changes were. Some participants took steps in helping others as a volunteer, peer support worker, or alternative therapist. Several participants mentioned a change in religiosity or spirituality-becoming more intensely involved in religion by taking courses or doing relevant study, such as theology or philosophy, or becoming a member of a different, more evangelical church.

\section{Pathological features of the experiences}

As mentioned above, in most interviews an intermingling of medical and religious concepts was present. In this section, we will first address the way participants tried to draw demarcation lines between genuine spirituality and signs of bipolar disorder. Second, we will discuss the 'costs' of their experiences, as they described them.

Distinction The distinctions participants mentioned between religious phenomena and pathology often corresponded with psychiatric symptomatology. For example, they referred to being overly preoccupied with the experience owing to the "the manic drive" (P8); excessive "magical thinking" (P23); megalomania - considering yourself the "nicest and most interesting religious person" (P5); and the derailment of experiences of unity, connectedness, and love (P25, P28) into frightening experiences (P14, P25). Other pathological features mentioned were related to the environment: extreme talkativeness about the experiences (P22) and "neglect of others" (P8) owing to obsession with the experiences. For a few participants, the incoherence of their notes written about the manic experiences pointed in retrospect to the pathological features of these occurrences (P1, P3, and P8).

Costs Almost a third of the participants reflected on the 'costs' of mania, however enriching the religious experiences in themselves might have been. The costs included admission to the hospital and leaving children and loved ones at home; long periods of recovery; loss of cognitive functions, 
job, or partner; and shame about the consequences of mania. Most participants within this group who had gone through several manic episodes concluded they did not want to go through one ever again. P27 summarized the evaluation of his religious experiences as follows:

It did give me some wonderful insights, though, because both times I had a real breakthrough. And I actually realized that I do not need anything to be happy. And that is something I have often thought about later on. But the fact is that I became psychotic, and the more often you have psychotic episodes, the easier it is for these episodes to occur. So, I think no, it is too high a price to pay. (male, no religious education, Protestant)

\section{Exclusively spiritual and exclusively medical explanations}

Only two participants in the study applied an exclusively spiritual interpretation to their religious experiences and two an exclusively medical interpretation. The first two emphasized that their experience had to be viewed exclusively in religious or spiritual terms. Although they had utilized mental health services, they objected to the diagnosis of BD. As P30 remarked: "a manic episode, I've come to view it differently... .. We call it bipolar disorder. In other cultures, they perhaps refer to it as being spiritually gifted" (male, new spirituality). For these two participants, the experiences were expressions of a spiritual crisis, and they had a critical attitude toward mental health care.

The second two participants considered their experiences as exclusively pathological and a sign of BD. They viewed them as "illusory, not a worthwhile goal to strive for during illness episodes" (P11, male, anthroposophical) or a "disruptive experience" P3 (man, strict pietistic Protestant). In both cases, their own religious tradition was a reference point in the valuation of the experiences as not genuinely religious. Their personal faith was a reference point for coping with the diagnosis of BD as well. They viewed it as a given that they had to deal with, with the help of a spiritual reality or God. Both had a sophisticated attitude toward religious experiences in general. P11 had written a booklet about balanced spiritual practice in the tradition of Rudolf Steiner. P3, a theologian, remarked that in fact all human experiences come from God. In that sense, he said, there is no reason to set 'special experiences' apart.

In the following sections, two themes that influenced the participants' interpretation process of their experiences over time are discussed. First, the theme 'mood swings and development of the illness' is addressed. Not only did the content of the experiences appear to be episodedependent (Ouwehand et al. 2018), but the ways participants interpreted their religious experiences were influenced by mood swings and the different phases in the development of the illness. 'Recurring doubt and distance from religiosity,' the 'discrepancy' between the experiences and normal daily life, and 'finding balance' were subthemes here. Second, 'communication' was an important theme in the interpretation process. The approach of others (relatives, professionals, peers, and clergy) often determined the direction of the interpretation process or its practical consequences. In this section, participants' expectations of treatment pertaining to their experiences are also described.

\section{Mood swings and development of the illness}

The way participants interpreted their religious experiences was not static. The interviews included evaluations of how their interpretation had changed over the years, often depending 
on illness episodes but also on development of the illness over time and on illness management. The process of coming to terms with the illness and with religious experiences that had something to do with BD was often a process of ups and downs - of getting stuck temporarily and of finding balance.

Recurring doubt and distance from religiosity Many participants reported periods of doubt about the religious significance of their experiences during the course of their illness. Doubt could arise during hospital admission, when confronted either with other patients who had, in their eyes, strange experiences or with a medical explanation for their own experiences. P34, a fundamentalist Protestant woman, reported she became very confused by the diagnosis of BD II because, up to that moment, she had considered her mood fluctuations as ways in which God was challenging her (in hypomania) and teaching her modesty (in depression).

Doubt could arise during the depressive episodes following mania, and the entire religious life of participants could become unsettled. Absence of faith or spirituality and absence of the divine was a prominent characteristic of depression in the sample. P24 described how his whole world collapsed during depression. After his mystical experiences during mania, he thought he had found a spiritual path in his life in Sufism, but during and after a bout of depression he strongly doubted the truth of his experiences and kept his distance from any kind of religiosity for about a year. Some participants described keeping a distance from faith and spirituality at periods in their lives due to the illness. Several participants described depression as a closing off of oneself from the divine or the spiritual dimension, a period of meaningless abyss full of despair and self-reproach. Religious experiences that had occurred during mania were interpreted by some as pathological during depression: "I thought: this is illness - I don't want to have anything to do with it (the experience) anymore" (P1, female, evangelical Protestant).

Several patients reflected on how their interpretation of their experience fluctuated over time; conclusions drawn during a certain episode or phase of life were revised later on, often more than once. P37 reported how difficult it was to get a grip on this tedious process of changing views about himself, God, and the world. Even while speaking during the interview, he was aware of the fact that he would have expressed himself differently if he had been hypomanic or very depressed. P6, when she recovered from a bout of psychotic depression, dismissed a religious interpretation of her experiences.

If you are stable, then you look back on depression and regard sin as something that has been made up. But when you are depressed, then you are afraid that the devil really exists. (female, brought up in a fundamentalist Protestant household, interested in new spirituality).

Discrepancy Two participants explicitly struggled with the fact that religious experience and daily life, when they had recovered from an episode of mania, remained separate domains. P18 for example, remarked:

And then I really feel, yes, I had a lot of experiences and they were beautiful, but what can I do with them? Those experiences cannot easily be integrated in daily life, and in fact you have to keep your distance from them and continue in the "normal" world; for me, that is difficult. (male, from a Roman Catholic background, hybrid religiosity)

The experiences lost their significance for some participants, but for these two the discrepancy between their experiences and ordinary life remained painful. The interview itself was a 
moment of partly reliving their experiences or suffering the grief of unresolved longing for their religious experiences, even when they had happened many years ago. A few others, who were still recovering from an episode, came to realize how alarmingly close they were to an experience they did not want to happen again. Even when religious experiences during illness episodes were valued as enriching, the struggle to integrate them into one's life story was apparently challenging for many participants.

Finding balance The challenge of finding balance was a theme in more than a third of the interviews. For some participants, their quest for meaning had become less intense over the years, related to their acceptance of the illness, the decreasing frequency of destabilizing mood swings, and improved illness management. These participants reported they had overvalued their religious experiences when they were younger, like "Icarus, flying too close to the sun" (P11). They stressed the need to put their religious experiences into the right perspective. A few expressed the opinion that in certain spirituality circles, religious experience was given too much importance. These 'experienced' participants (both with a Christian and a new spirituality affiliation) had learned that religious experience and the quest for meaning must be balanced with more earthly things such as sport, working in the garden, caring for relatives, doing practical things in daily life, meeting other people in church, or carrying out simple spiritual practices. For these participants, their religious views helped them to put their experiences into perspective, such as for P8, who made the distinction between experiences as hallel (Hebrew for 'praising God'), or gallel (Hebrew for 'blasphemy'). They stressed that religious experiences in and of themselves were not a criterion for genuine spirituality but fostered spiritual growth (P32) and an (ethical) orientation in life (P10, P22, P27).

\section{Communication}

'Communication' about the religious experiences participants had gone through during illness episodes was an explicit interview topic, but the theme also came to the fore indirectly at other moments in the interviews through the many remarks on the influence other people had had on the process of interpretation. This influence was sometimes perceived as supportive and understanding but in other cases as undermining or unhelpful. Participants expressed two clear needs with regard to communication about their experiences: 'recognition' and 'a critical sounding board.'

Recognition and acceptance Many participants expected recognition of the religious importance of their experiences. They expressed their longing for nonjudgmental listening; the attitude of the dialogue partner - not questioning the veracity of the experiences - was an important condition for their willingness to share their experiences. They described the loneliness of their quest for meaning when sharing had been impossible and their gratitude for people with whom they had been able to share their experiences. Many participants explicitly appreciated the opportunity to participate in the study.

Critical sounding board Several participants stressed that recognition and acceptance did not just mean confirmation of their experiences. A critical sounding board was needed as well, either to relativize the content or participants' interpretation of the experiences or to give feedback regarding the attitude of participants toward others - talking too much or going too 
far in pursuing spirituality. P37 explained how his best friend, not a believer at all, teased him gently about his experience in a respectful way. He appreciated the lightness this brought to the conversation, while at the same time his friend was recognizing that the experience was about things of immense concern to P37.

In the following paragraphs, communication with different groups of people and the themes that are illustrative of communication within each group, are addressed: relatives and friends, health care professionals, peers, and clergy/hospital chaplains. Treatment expectations and tips participants gave are incorporated as an integral part of the discussion of each group. These include comments on attitude as well as practical tips to improve communication about religious experiences.

Relatives and friends Ambivalence toward worried partners or parents was present in several interviews. Some participants shared their religious affiliation with their partner, and their experiences and possible derailment were part of a mutual exchange. However, close relatives could be too concerned as well. They were sometimes guardians in a double sense: preventing derailment as well as preventing fulfilment. Other participants reported disagreement with or anger toward relatives or friends about the topic. They mentioned how painful it was to realize that their worthwhile and impressive experiences were seen by close relatives as illness. P20, who did not want to put the relationship with her husband at risk, constantly felt pressure to "color just inside the lines." The sorrow over the loss of an experience that had occurred ten years before and had given her much happiness touched her while describing it during the interview. The impossibility of sharing it with others had made her uncertain of herself, she said. Several participants stated that the way their experiences were viewed by others, or the fear of others due to the strangeness of the experiences, had led them to taking a negative stance toward the experience. Other reactions included a reluctance to talk about it with anyone, (temporarily) keeping a distance from any form of religiosity to prevent trouble with relatives, or rejecting relatives who were too critical.

Mental health care professionals Remarks about actual or expected communication with mental health care professionals often had a more general character and did not specifically pertain to religious experience. The medical language of professionals was regularly experienced as reductionist and lacking a perspective of the whole person behind the symptoms. Half of the participants perceived the medical model as undermining and diminishing their experiences, or they described the professionals as being disrespectful or uninterested in faith and spirituality in general. In most consultations, the general condition and daily functioning of the patient were addressed; according to several participants, neither faith nor spirituality was regarded as a source for recovery. One-third of the sample missed reflecting on the content of their religious experiences or psychosis in general. Sharing is more than informing, P19 stated: "It is all about existential questions, even if the experiences manifest themselves as "crazy.",

Another stumbling block in communication was perceived differences in philosophy of life. Some participants pointed out that the discrepancy between a medical and a religious model had to do with differences in basic assumptions about what being human is. They did not find much opportunity to talk about 'the soul' or non-natural explanations of what had happened. "I find most psychiatrists skeptical," P36 remarked, "and science is their religion." For this reason, some of the participants did not expect psychiatrists to be able to address their spiritual needs, and they turned to alternative therapists or friends who were engaged in spirituality. Their quest for more spiritual explanations had varying degrees of success because the vulnerability to $\mathrm{BD}$ was not always recognized in the alternative circuit or in the church. 
Others mentioned a shared frame of reference as a necessary condition for discourse on religiosity or emphasized the need for education of mental health care professionals on this point.

The actual or expected lack of interest of professionals had made several participants reluctant to explore their experiences in treatment. A few participants therefore stated explicitly that a proactive attitude among professionals could be helpful. They suggested investigating whether religiosity or religious experience was important to the patient for disease management and referring them to hospital chaplaincy.

Positively valued communication with mental health care professionals was less prominent in the interviews than were critical remarks, especially with regard to religiosity and religious experience. Positive remarks about communication pertained to the opposite of the aforementioned attitudes and were mentioned more often about nurses, case managers, and psychotherapists than psychiatrists. Participants positively valued felt interest, openness to the patient's interpretations, shared decision-making (for example, with regard to medication that could influence spirituality), encouraging patients in their quest for meaning, and the professional showing vulnerability or fallibility, which was perceived as shared humanity.

Another positively evaluated aspect relating to mental health care was professional expertise. The medical outlook was appreciated by several participants as complementary and necessary to their religious explanations. A few mentioned that professionals had at moments been right to dampen their religious enthusiasm, although they could only appreciate this in retrospect. They had "planted a seed in my being that had germinated later on," P26 stated.

Peer support Contact with peers with comparable experiences was reported as helpful or mentioned as a need. This contact was experienced during hospital admission and, for a few, within the context of a religious community as a result of admitting their diagnosis. P23, a peer support worker, explained how she offered different explanations pertaining to religious experience in her contact with patients as possibilities for reflection. It was a recurring theme in her work and had been a healing experience for herself, she said.

Sharing religious experience in peer support groups appeared to be only successful under certain conditions. Different phases of the illness and incongruence of religious background (evangelical faith and new spirituality, for example) impaired mutual understanding, some participants reported, especially when adequate guidance of the session was lacking.

Clergy and hospital chaplains Only a few participants reported a supportive relationship with clergy in a religious community, and nobody made mention of any contact between mental healthcare professionals and clergy. This would have been very helpful in valuing their religious experience, a few participants stated. Several participants also pointed to the importance of a nonjudgmental space in which the experiences could be explored and valued, either individually or in a group. P20 reported that the hospital chaplain had left the interpretation of her experiences open and neither explained them as pathological nor as revelatory. This had helped her to let go of worrying about them. P37 mentioned that the interpretations of different religious and spiritual traditions the hospital chaplain had offered him had helped him to reduce self-stigma. Openness, acceptance, advice, relativism, counterbalance, trust, and prayer were other words in the interviews pertaining to the attitude of hospital chaplaincy (Fig. 1). 


\section{Discussion}

\section{Intertwinement of the religious and the pathological}

The focus of this study was on the way persons with BD interpret their religious or spiritual experiences related to illness episodes. We found that an intense religious quest was at times a direct consequence of religious experiences during mania. An important result was that most participants endorsed mixed religious and medical explanations for BD and for their religious and spiritual experiences related to BD. Religious experiences were seen as having an influence on participants' lives and fostering spiritual growth but as also potentially having pathological characteristics. This finding corresponds with the results of a qualitative study into the meaning of first-episode psychosis, implying that participants combined various systems of explanation for their psychotic experiences by drawing on medical explanatory models and the cultural and religious repertoire of the wider society (Larsen 2004).

\section{Religious experience and autobiography}

Part of the sample viewed their religious experiences related to illness episodes as a necessary phase in their lives. In their opinion, addressing the content of the experiences was crucial for overcoming trauma and coming to terms with the past. The view of the relatedness of religious experiences to autobiography has long roots. James (1902/1917) and Boisen (1936) regarded religious experiences as resolutions of inner conflicts and disharmony. For both authors, the result of the experiences, marking the dissolution of the inner conflict defined in transcendental terms, distinguishes genuine religiosity from psychopathology (Hood et al. 2009). James does not specifically refer to religious experience within the context of mental illness, whereas Boisen takes his own experiences with psychosis as a starting point for reflection. The findings of the present study do not suggest that a clear distinction can be made between genuine religiosity and psychopathology. The boundaries between the two are often blurred and part of an ongoing process of interpretation. This is consistent with several studies into Boisen's own interpretation of his psychotic religious experiences that relate them to his autobiography,

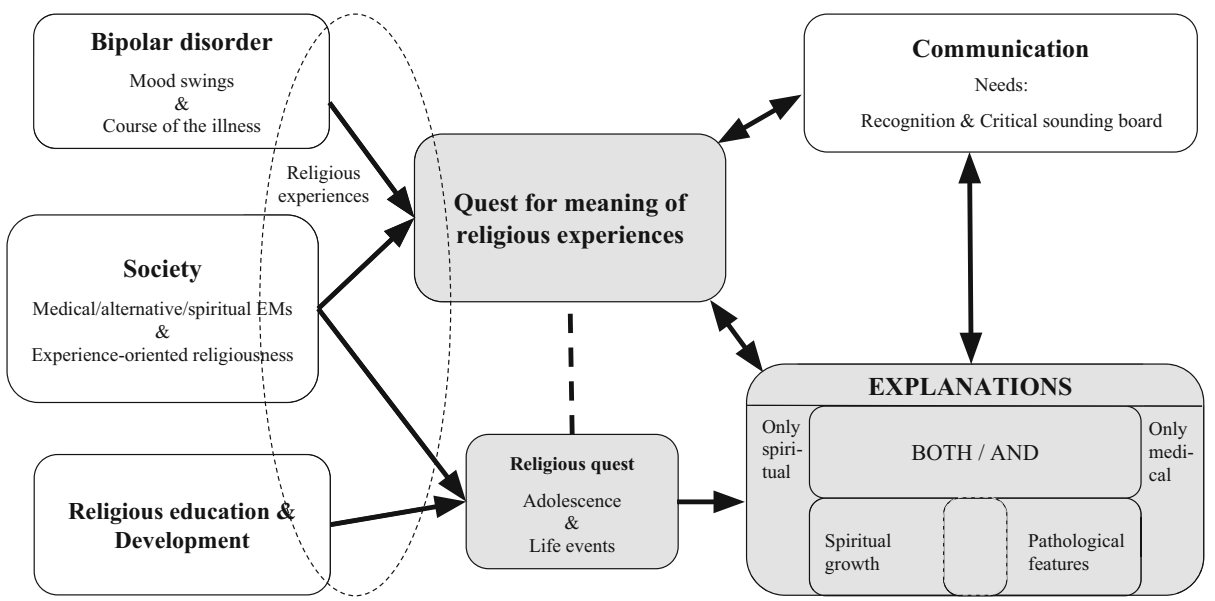

Fig. 1 The process of interpretation of religious experiences related to bipolar disorder, the various influences on this process found in the analysis, and the different explanations participants attributed to their experiences 
including his history of schizophrenia (Arends 2014; Stroeken 1983). The fact that patients draw a relationship between psychotic religious experience and autobiography can be an important issue in treatment for them.

More recently, Bock (2000) theorizes along similar lines, albeit his interest concerns the more general process of meaning-making and the integration of psychotic experience in autobiography. One of the results of his qualitative study into experiences of untreated psychosis with regard to religion is that experiences with religion in an oppressive atmosphere can foster psychosis, but religiosity can also be a protective factor and helpful in integrating psychotic experiences into a person's life story. Bock's theoretical insight is the basis for the Subjective Sense in Psychosis Questionnaire used to measure coherence and comprehension (making sense of the phenomenon) in psychotic disorders (Klapheck et al. 2012). One of the outcomes of this study was that $76 \%$ of the included patients assumed a relationship between their autobiography and the emergence of psychosis.

\section{The transient character of the interpretation process}

The second research question pertained to the process of the interpretation of religious experiences over the participant's lifespan. This process showed much individual variation and modification over time. Participants perpetually weighed and revalued medical and religious explanations and tried to integrate scientific knowledge about BD with alternative or spiritual views on the illness. Religious upbringing and affiliation had an influence on the process, but mood swings, development of the illness, and communication with others about the experiences affected the course and direction of explanations as well. One of the results of the present study was that several participants with a longer history of BD concluded that their passionate religious quest at the initial phase of $\mathrm{BD}$ had led to derailment and exaggeration of their religious experiences. In their view, these experiences should be balanced with more earthly, everyday, and sober aspects of religiosity. This corresponds with the study of Brett et al. (2013) in which lower levels of distress over anomalous experiences were predicted by "more neutral responses, which were characterized by not actively pursuing the experiences, preventing them, or intellectually exploring them" (p. 222).

The transient character of religious explanations for mental illness found in the present study corresponds with the results of a study of Huguelet et al. (2010). In a group of patients with schizophrenia and schizoaffective disorder, a spiritual view of their illness (broader than only focusing on religious experiences) persisted in $31 \%$ of the sample over a period of three years. However, only $38 \%$ of the patients did not explain their illness in spiritual terms over the entire study period. Larsen (2004) also emphasized the ongoing development of the interpretation process of first-episode psychosis, which was influenced by various social and institutional contexts and communication media. Ouwehand and colleagues (Ouwehand et al. 2019) found in their study of the prevalence of religious experiences and their perceived lasting influence in a BD outpatient sample $(n=196)$ that the perceived lasting influence of religious experiences varied from 4 to $36 \%$ across various types in the total sample. This referred to onefifth to two-thirds of the participants who reported religious or spiritual experiences. All experiences were significantly related to mania in this study. One of the conclusions was that psychotic experience with religious or spiritual content may have a transitional nature for some but is interpreted religiously after recovery and perceived as having life-changing influence by others. The outcome of the latter study puts in perspective the high number of participants in the current study who reported a lasting influence of their religious experiences. The result in 
the current study could be explained by the high religious involvement and the higher than average theological and/or spiritual education of the sample.

\section{Conflicting explanatory models in mental health care}

With regard to communication in mental health care about religious experiences, this sector as a whole in our study was not evaluated as being very helpful, despite participants' appreciation for individual professionals and their medical, psychological, and nursing expertise. Much of the quest for meaning took place outside the hospital. Yet, conflicts over treatment were less apparent than in the studies of Mitchell and Romans (2003) and Stroppa and Moreira-Almeida (2013). This might be due to the high educational level and underrepresentation of ethnic and religious minorities in the current study. Another reason could be a positive bias toward mental health care professionals. Although many participants were critical of psychiatry, they were mostly well informed about their medical condition and its consequences. This implies that psycho-education about the illness had had some effect. Besides, many participants had a relationship with a professional at the time of the interview, even though they missed having spiritual or existential reflection on their experiences and BD in general.

Brett and colleagues (Brett et al. 2013) found in their study on anomalous experiences in clinical and nonclinical populations that perceived social support and understanding was one of the predictors of lower distress as a reaction to such experiences. This finding corresponds with the themes of recognition of the value of religious experiences and the need for a critical sounding board to evaluate the influence of $\mathrm{BD}$ on the experiences. According to the participants, both can contribute to a better therapeutic or pastoral relationship with regard to religious experiences.

\section{The need for adequate communication platforms}

Most participants had a social network, but it was not always supportive of the participants' religious quest. In some cases, relatives' concerns about hyperreligiosity and conflicts regarding the experiences were an issue. In addition, religious experiences could not always be shared in relevant religious or spiritual contexts. This might be due to the highly individualized and networked character of nontraditional religiosity and spirituality in a secularized society (De Hart 2011, De Hart 2014; Van Harskamp 2000). Another reason could be that, even within churches, religious experience is sometimes ignored or not seen as relevant (Van den Berg 1988; van der Zwaag 2007). Some participants had explored their religious experiences in individual pastoral counseling or in support groups led by the hospital chaplaincy in mental health care, but the potential contributions these made were not systematically integrated into their treatment.

The current study showed the need for dialogue and the exploration of religious experiences in the sample, although this need would probably be less prominent in a more representative sample of persons with BD as the participants had a more than average interest in religion and spirituality. A narrative approach that encourages people to explore their experiences in connection to their life stories, as often used in hospital chaplaincy, could be better integrated into the entire treatment process. Structured guidance, expertise in BD, and bridgeable differences in religious background were mentioned as a prerequisite for support groups on the topic. The internet could be a medium for exchange, as well, because it was an important source of information. However, such exchange would only be helpful under the abovementioned conditions. 


\section{Religious and spiritual guidance}

Religious and spiritual traditions offer guidelines for evaluating the lasting influence of religious experience. For example, in the letters of Paul, the fruit of the Spirit is called "love, joy, peace, forbearance, kindness, goodness, faithfulness, gentleness and self-control" (Gal. 5:22-23 NIV). Religious ecstasy needs a direction, which can vary in different religious traditions but always will connect experience with wisdom passed down over the ages and point to a fruitful religious or spiritual life individually as well as in connection with other people. This hermeneutical process is not without theological controversies, of course, because religious traditions value religious experiences differently. Nevertheless, the hermeneutical process in itself is necessary to make sense of the experiences. Lasting influence or the 'fruits' of the experience can be evaluated in the treatment relationship (Braam and Verhagen 2016; James 1902; Sims 2016), but the evaluation of the consequences for daily life transcends psychiatric treatment because it involves ethical and religious choices.

\section{Discussion of religious experiences in the congregation}

Discussion of religious experiences can be an important topic for those with BD who are in treatment, but it can also contribute to the life of the church. The transient character of religious experiences and explanations thereof raises theological questions about the value of religious experience because mood fluctuation is not a unique feature of BD. In Protestant theology, there has been much critical debate on religious experience as a ground for revelation since Karl Barth's rejection of any form of natural theology. The tendency in Western society toward the experiential aspect of religion and on personal spiritual growth, both in new spirituality and in the growing evangelical movement, asks for renewed theological reflection on religious experience in the traditional churches.

The theologian Aartjan van den Berg, originally a Barthian, developed a model for integration of religious experience in congregational life of mainstream Protestantism (1988). He and Berthilde van der Zwaag explore in qualitative studies the transforming aspect of contemporary religious experiences in the Christian tradition. Both point to the long lasting positive influence on individual lives and at the same time the invisibility of the reported experiences in congregational life. Van den Berg clarifies not only the healing and directing influence of mystical experiences on individuals' lives, but also stresses their inspirational potential for social and political change (Sölle 1975), which can vitalize the congregation.

Van den Berg as wel as Ganzevoort end Visser (2009) incorporate the modern religious longing for a more direct encounter with the divine, both within and outside the Christian tradition, in their practical theological approach. At the same time, they stress the need for critical reflection on religious experience in dialogue with the Christian tradition. Their approach can contribute to a supportive context of open communication to explore religious experiences of those both with and without a BD diagnosis. This could have a 'normalizing' and stress-reducing effect on the interpretation of experiences related to illness episodes (Brett et al. 2013). Ganzevoort stresses the nurturing of diversity in interpretations, instead of dogmatic evaluation, as important for the pastoral approach to religious experience (2012). Such a context of "opening up communication with God and people" (Schillebeeckx 1975) is not self-evident, but it is a potential of religious communities. 


\section{"The Awful Rowing toward God" (Sexton 1999)}

In the current study, participants reported religious experiences during mania with much more enthusiasm than they reported those during a depressive period. However, depression is a recurring condition in $\mathrm{BD}$ and determines the course of the illness to a large extent (Kupka 2009). In The Awful Rowing toward God, Ann Sexton describes her experience of the absence of God in depression ("God went out of me / as if the sea dried up like sandpaper, / as if the sun became a latrine." ("The Sickness unto Death," p. 441), and her desperate longing for God ( "but I am rowing, I am rowing / . . but there will be a door / and I will open it / and I will get rid of the rat inside of me, / the gnawing pestilential rat. / God will take it with his two hands / and embrace it." ("Rowing," pp. 417-418). These two poems contrast sharply with Sexton's moments of ecstatic joy and gratitude at other moments ("So while I think of it, / let me paint a thank-you on my palm / for this God, this laughter of the morning / lest it go unspoken." ("Welcome Morning," p. 455). Anne Sexton completed corrections of The Awful Rowing toward God before her death in 1974. The poetry collection was published posthumously in 1975 .

Swinton and Mowat (2006) describe phenomenologically how depression erodes meaning and faith. They characterize this process as a spiritual and existential crisis, and this is comparable to descriptions of depression in our study. In clinical and pastoral practice, attention to negative aspects of religiousness is important. The abyss of meaninglessness and absence of the divine, frightening or incomprehensible experiences, grieving the loss of 'paradise' in (hypo)mania, and grieving the losses in other domains of life because of serious mental illness are not primarily medical matters but require existential and theological reflection. The containment of both loss and longing in coming to terms with illness is an important role of the hospital chaplain or spiritual counselor (Muthert 2012). Religion offers a vocabulary that gives expression to the ambiguities that living with a mental disorder such as BD entails.

\section{Limitations}

An effort was made to include participants of religious and ethnic minorities and participants in the initial phase of $\mathrm{BD}$, but these groups were underrepresented in the study. The sample was on average highly educated and more than average religiously affiliated. In this sense, it was not representative of BD patients. The interviews took place when participants had recovered from an episode of illness and involved retrospective interpretation of experiences that had often occurred some years ago. Although the contribution of the current study toward the understanding of spiritual needs at the time of illness episodes is limited, this retrospective interpretation gives considerable insight into the way persons with BD struggle to make sense of such experiences and try to integrate them into their life story.

\section{Conclusion}

Interpretation of religious experiences in the context of BD is a challenging endeavor for people with this diagnosis. It implies a constant process of autobiographical reflection, which is influenced by original and present religious affiliation, mood swings, course of the illness, and communication with others. Most participants in the current sample endorsed a mixed medical-religious model to interpret their experiences and BD in general, and a variety of 
medical and religious or spiritual sources supported the interpretation process. Mental health care was evaluated as not being very helpful in dealing with religious experience with regard to illness management, and contributions of the hospital chaplaincy was viewed as not integrated into the treatment. A majority in the present sample expressed the need for open dialogue about their religious experiences within their treatment and the opportunity to explore and critically evaluate them. Yet, more research is needed to estimate this need in a representative sample of the entire patient population with BD. The expertise of hospital chaplains in the hermeneutical processes involved in valuing religious experiences should be integrated into a multidisciplinary approach in treatment. A five-minute summary of the research project is available on YouTube: https://www.youtube.com/watch?v=MxrGvWr2zMg.

Acknowledgments We would like to acknowledge the assistance of Kwok Wong, Dirk Kwakkel, Charissa Zijp, and Joke Meeuse, trainees in psychiatry, with the interviews and of Elizabeth Harding with the English version of the manuscript.

\section{Appendix: Interview Procedure}

\section{Demographic data}

Age, gender, single/married or cohabitating, children

Formal education, work/volunteer

\section{Diagnosis}

When were you diagnosed with bipolar disorder? Which kind of bipolar disorder do you have? How many (manic/depressive) episodes have you experienced?

Do you use medication?

Do you have a therapist? Do you agree that we may contact your therapist if your diagnosis is not clear to us?

\section{Religious background and development}

Were you brought up in a religious household? Could you tell us more about how important religion/spirituality was in your family? How did your faith/spirituality change over the years? How important is faith/spirituality for you at the moment? Would you describe yourself as a religious or spiritual person? What does that mean to you?

Are you a member of any organized form of religion or spirituality? (How much involvement and how important is it).

Do you follow a certain spiritual path? (Explanation of the path).

How often do you go to church, mosque/synagogue, or a religious or spiritual gathering?

How often do you pray or meditate/perform religious rituals in your daily life?

Do you read about religion/spirituality? How often, and what kind of literature?

Did faith or spirituality play a role in your life before you were diagnosed?

Is your religiosity/spirituality a help for you or not with regard to bipolar disorder? Can you give an example? 


\section{Experiences during mania/depression/stable periods}

The results of these topics are presented in another publication. We asked as precisely as possible what the participant had seen, heard, felt, experienced, etc. When the participant started to elaborate on the interpretation, we tried to bring the account back to the experience itself.

\section{Interpretations of religious experiences during illness episodes}

How do you evaluate your religious experiences during mania/depression at this moment? What kind of experiences are they, from your perspective?

To what extent do you consider your experiences as an expression of your illness or as an authentic religious experience, or perhaps both?

Is the interpretation of you experiences during illness episodes an issue for you at this moment? Have you found meaning in the experiences, are you still struggling to find meaning in them, or have you found an answer to your questions? Could you describe to us how you interpreted your experiences? Has your interpretation changed over time?

Have your experiences changed your view of life? How?

Have they changed your view of yourself? How?

Have they changed your daily life? How?

Do you think that the course of your illness has influenced your perception of religiosity/ spirituality? How?

Do you think that your religiosity/spirituality has influenced the course of you illness? How?

\section{Helpful and unhelpful interventions/reactions}

What has been helpful for you with regard to your experiences?

Did you talk about them with your partner/family/friends? What were their reactions?

Did you talk about them with other persons? Do you recall when this helped you and when not? Have you read about the experiences you have had (the internet, books, journals)? What was helpful for you?

What other things have helped you to make sense of your experiences?

\section{Treatment experiences and expectations}

Could you tell us about your experiences with mental health care with regard to your religious experiences?

What has been helpful and what not in the reactions of professionals? Can you give us examples?

If you think the approach has not been helpful, what do you need with regard to your experiences (during manic/depressive episodes, when stable)?

Which aspects of your religiosity/spirituality could have been supported in treatment (for example, religious practices, exercises, discourse about the content of the experiences, influence of medication on spirituality, etc.)

Are there any differences in the approach toward such experiences between different mental health professionals (nurse, case manager, psychologist, psychiatrist, hospital chaplain, or imam), in your opinion? Could you give examples? 
Did you consult other therapists or persons outside of mental health care to make sense of your experiences, for example your own pastor?

Could you describe whether this was helpful or not and how?

Have you ever received contradictory advice from mental health care professionals or others, such as a spiritual counselor or an alternative therapist? How did this work out for you?

Do you feel the need to share your religious experiences with other persons? In a group?

Do you think dealing with your religious experiences should be part of psycho-education or of treatment?

What advice would you give to others with bipolar disorder with regard to their experiencesthe do's and don'ts?

\section{Evaluation of the interview, tips}

Have you told us what you wanted to say or are there other remarks you would like to make? Do you have any suggestions for us as researchers? How do you evaluate the interview? Do you want the transcript sent to you to make corrections or give further explanation?

\section{Instructions}

Introduction of the study (why, history, etc.), of the interviewers, and of the role of the psychiatrist as interested listener instead of a clinical diagnostician. Explanation of personal involvement of the interviewers in the study. It is important to establish a relationship with the participants, since religious experiences are not often shared with psychiatrists and participants possibly feel constrained when talking about the subject with a psychiatrist.

Signing or collecting the informed-consent form.

The topic list is a guideline. The questions are meant as examples fort the interviewers, but the aim is to explore in more depth what participants have experienced by asking them to elaborate on what they initially mention. There is no need to follow the topic list strictly. When participants start with a recounting of their experiences or how they experienced hospitalization, that is okay.

The psychiatrist asks about the diagnosis and progression of the illness until it is clear or asks permission to consult the participant's therapist. Sometimes not all topics on the list can be addressed.

The description of religious and spiritual experiences and the process of interpretation after recovery are the most important topics and should be divided into separate subtopics as much as possible. This can be a challenge because persons with bipolar disorder can be very associative.

The first interviewer is in direct contact with the interviewee, invites him or her to elaborate on their experiences, and guides the process when participants become too associative. The second interviewer controls whether the important topics are dealt with and is responsible for keeping time.

At several times during the interview, the interviewer should summarize what the participant has said and ask for their feedback.

Evaluation is done at the end of every interview, and participants are told that additional documents can be sent to the researcher. 
Open Access This article is distributed under the terms of the Creative Commons Attribution 4.0 International License (http://creativecommons.org/licenses/by/4.0/), which permits unrestricted use, distribution, and reproduction in any medium, provided you give appropriate credit to the original author(s) and the source, provide a link to the Creative Commons license, and indicate if changes were made.

\section{References}

Altman, E. G., Hedeker, D., Peterson, J. L., \& Davis, J. M. (1997). The Altman self-rating mania scale. Biological Psychiatry, 42(10), 948-955.

American Psychiatric Association. (2013). Diagnostic and statistical manual of mental disorders (5th ed.). Washington, DC: American Psychiatric Association.

Appelbaum, P. S., Robbins, P. C., \& Roth, L. H. (1999). Dimensional approach to delusions: Comparisons across types and diagnoses. American Journal of Psychiatry, 156(12), 1938-1943.

Arends, C. (2014). If Billy Sunday comes to town-Delusion as a religious experience? The biography of Anton T. Boisen from the perspective of foundational theology. Zürich: LIT Verlag.

Berghuijs, J. (2016). Nieuwe spiritualiteit en sociale betrokkenheid [New spirituality and social engagement]. Psyche en Geloof [Psyche and faith], 27(1), 11-30.

Berghuijs, J. (2017). Multiple religious belonging in the Netherlands: An empirical approach to hybrid religiosity. Open Theology, 3, 19-37.

Berghuijs, J., Pieper, J., \& Bakker, C. (2013). Being 'spiritual' and being 'religious. Journal of Contemporary Religion, 18(1), 15-32.

Bernts, T., \& Berghuijs, J. (2016). God in Nederland,1966-2015 [God in the Netherlands, 1966-2015. Utrecht: Uitgeverij Ten Have.

Biggerstaff, D. L., \& Thompson, A. R. (2008). Interpretative phenomenological analysis (IPA): A qualitative methodology of choice in healthcare research. Qualitative Research in Psychology, 5, 173-183.

Bock, T. (2000). Psychosen zonder psychiatrie [Psychoses without psychiatry] (M. Stoltenkamp, Trans.). Candide: Amsterdam.

Boeije, H. R. (2010). Analysis in qualitative research. London: Sage.

Boisen, A. T. (1936). The Exploration of the inner world: A study of mental disorder and religious experience. New York: Harper \& Brothers https://archive.org/details/in.ernet.dli.2015.18254.

Braam, A. W., \& Verhagen, P. J. (2016). Religie, spiritualiteit en psychiatrie [religion, spirituality and psychiatry]. Houten: Accredidact.

Brett, C., Heriot-Maitland, C., McGuire, P., \& Peters, E. (2013). Predictors of distress associated with psychoticlike anomalous experiences in clinical and non-clinical populations. British Journal of Clinical Psychology, 2, 213-227.

Bruner, J. (1991). The narrative construction of reality. Critical Inquiry, 18. http://www.semiootika. ee/sygiskool/tekstid/bruner.pdf, 1-21. Accessed 17 July 2018.

Cook, C. C. H. (2016). Narrative in psychiatry, theology and spirituality. In C. C. H. Cook, A. Powell, \& A. Sims (Eds.), Spirituality and narrative in psychiatric practice (pp. 1-14). Glasgow: Bell \& Bain.

De Hart, J. (2014). Geloven binnen en buiten verband [believers within the fold and without]. Den Haag: The Netherlands Institute for Social Research Publications. https://www.scp.nl/Publicaties/Alle_ publicaties/Publicaties_2014/Geloven_binnen_en_buiten_verband. Accessed 23 Feb 2017

Gallemore, J. L., Jr., Wilson, W. P., \& Rhoads, J. (1969). The religious life of patients with affective disorders. Diseases of the Nervous System, 30(7), 483-487.

Ganzevoort, R. R. (2012). Ruimte voor het heilige: Christusverschijningen [Room for the sacred: Appearances of Christ]. Handelingen/Acts, 39(1), 19-29.

Ganzevoort, R., \& Visser, J. (2009). Zorg voor het verhaal: Achtergrond, methode en inhoud van de pastorale begeleiding. [Care for narrative: Background, method, and content of pastoral counseling]. Zoetermeer: Uitgeverij Meinema.

Grover, S., Hazari, N., Aneja, J., Chakrabarti, S., \& Avasthi, A. (2016). Influence of religion and supernatural beliefs on clinical manifestation and treatment practices in patients with bipolar disorder. Nordic Journal of Psychiatry, 70(6), 442-449.

De Hart, J. (2011). Zwevende gelovigen: Oude en nieuwe spiritualiteit [the floating faithful: Old and new spirituality]. Amsterdam: Uitgeverij Bert Bakker.

Helman, C. G. (2001). Culture, health and illness. London: Hodder Arnold.

Hood, R., Hill, P., \& Spilka, B. (2009). The psychology of religion. New York: Guilford Press. 
Huguelet, P., Mohr, S., Gilliéron, C., Brandt, P.-Y., \& Borras, L. (2010). Religious explanatory models in patients with psychosis: A three-year follow-up study. Psychopathology, 43(4), 230-239.

James, W. (1902/1908). The varieties of religious experience. A study in human nature. New York, London, Bombay: Longmans, Green, And Co. https://archive.org/details/varietiesreligi03jamegoog/page/n7. Accessed 15 Jan 2017.

Klapheck, K., Nordmeyer, S., Cronjäger, H., Naber, D., \& Bock, T. (2012). Subjective experience and meaning of psychoses: The German subjective sense in psychosis questionnaire (SUSE). Psychological Medicine, 42, $61-71$.

Kleinman, A. (1988). The illness narratives. New York: Basic Books.

Kleinman, A. (1991). Rethinking psychiatry. From cultural category to personal experience. New York: The Free Press.

Koenig, H. G. (2007). Religion, spirituality and psychotic disorders. Archives of Clinical Psychiatry, 34(1). www. scielo.br), 95-104. https://doi.org/10.1590/S0101-60832007000700013. Accessed 26 Oct 2017.

Kroll, J., \& Sheehan, W. (1989). Religious beliefs and practices among 52 psychiatric inpatients in Minnesota. American Journal of Psychiatry, 146(1), 67-72.

Kronjee, G., \& Lampert, M. (2006). Leefstijlen en zingeving [Lifestyles and meaning]. In W. B. H. J. Van de Donk, A. P. Jonkers, G. J. Kronjee, \& R. J. J. M. Plum (Eds.), Geloven in het publieke domein [Believing in the public domain] (pp. 171-209). Amsterdam: University Press.

Kupka, R. (2009). Beloop op korte en lange termijn [Short- and long-term course]. In R. Kupka, E. KnoppertVan Der Klein, \& W. Nolen (Eds.), Handboek bipolaire stoornissen [manual of bipolar disorders] (pp. 7799). Utrecht: De Tijdstroom Uitgeverij BV.

Kupka, R., \& Nolen, W. (2009). Classificatie en diagnostiek [Classification and diagnostics]. In R. Kupka, E. Knoppert-Van Der Klein, \& W. Nolen (Eds.), Handboek bipolaire stoornissen [manual of bipolar disorders] (pp. 15-41). Utrecht: De Tijdstroom Uitgeverij BV.

Larsen, J. A. (2004). Finding meaning in first episode psychosis: Experience, agency, and the cultural repertoire. Medical Anthropology Quarterly. International Journal for the Analysis of Health, 18(4), 405-523.

Leamy, M., Bird, V., Le Boutillier, C., Williams, J., \& Slade, M. (2011). Conceptual framework for personal recovery in mental health: Systematic review and narrative synthesis. The British Journal of Psychiatry, 199, 445-452.

Michalak, E. E., Yatham, L. N., Kolesar, S., \& Lam, R. W. (2006). Bipolar disorder and quality of life: A patientcentered perspective. Quality of Life Research, 15, 25-37.

Mitchell, L., \& Romans, S. (2003). Spiritual beliefs in bipolar affective disorder: Their relevance for illness management. Journal of Affective Disorders, 75, 247-257.

Muthert, H. (2012). Ruimte voor verlies. Geestelijke verzorging in de psychiatrie [Room for loss: Spiritual care in psychiatry]. Tilburg: KSGV.

Ouwehand, E. (2015, July 13). Tussen hemel en hel: Onderzoek naar spirituele ervaringen en de bipolaire stoornis [Between heaven and hell: Research into spiritual experiences and bipolar disorder], https://www. psychosenet.nl/category/spiritualiteit/. Accessed 13 July 2015.

Ouwehand, E., Wong, K., Boeije, H., \& Braam, A. (2014). Revelation, delusion or disillusion: Subjective interpretation of religious and spiritual experiences in bipolar disorder. Mental Health Religion and Culture, $17(6), 615-628$.

Ouwehand, E., Muthert, J. K., Zock, T. H., Boeije, H., \& Braam, A. W. (2018). Sweet delight and endless night: A qualitative exploration of ordinary and extraordinary religious and spiritual experiences in bipolar disorder. International Journal for the Psychology of Religion, 28(1), 31-54.

Ouwehand, E., Braam, A. W., Renes, J. W., Muthert, J. K., Stolp, H. A., Garritsen, H. H., \& Zock, T. H. (2019). Prevalence of religious and spiritual experiences and the perceived influence thereof in patients with bipolar disorder in a Dutch specialist outpatient center. Journal of Nervous and Mental Disease, 207(4), 291-299.

Possamai, A. (2005). In search of New Age spiritualities. Cornwall: MPG Books.

Regeer, E., Ten Have, M., Rosso, M., Vollenbergh, W., \& Nolen, W. (2004). Prevalence of bipolar disorder in the general population: A reappraisal study of the Netherlands mental health and incidence study. Acta Psychiatrica Scandinavica, 110, 374-382.

Rush, A. J., Trivedi, M. H., Ibrahim, H. M., Carmody, T. J., Arnow, B., Klein, D. N., \& Keller, M. B. (2003). The 16-item quick inventory of depressive symptomatology (QIDS), clinician rating (QIDS_C), and self-report (QIDS-SR): A psychometric evaluation in patients with chronic major depression. Biological Psychiatry, 54, 573-583.

Schillebeeckx, E. (1975). Jezus, het verhaal van een levende. Bloemendaal, the Netherlands: H. Nelissen. English edition: Jesus, an experiment in Christology (p. 1979). New York: Seabury.

Sexton, A. (1999). The complete poems. Boston Houghton Mifflin Company.

Sims, A. (2016). Psychopathology and the clinical story. In C. C. H. Cook, A. Powell, \& A. Sims (Eds.), Spirituality and narrative in psychiatric practice (pp. 25-39). Glasgow: RCPsych Publications. 
Smith, J., \& Osborn, M. (2008). Interpretative phenomenological analysis. In J. Smith (Ed.), Qualitative psychology (pp. 56-80). Los Angeles: Sage.

Sölle, D. (1975). Die Hinreise: Zur Religiösen Erfahrung-Texte und Überlegungen [The silent cry: Mysticism and resistance]. In Stuttgart. Germany: Kreuz-Verlag.

Spearing, M. K., Post, R. M., Leverich, G. S., Brandt, D., \& Nolen, W. (1997). Modification of the clinical global impressions (CGI) scale for use in bipolar illness (BP): The CGI-BP. Psychiatry Research, 73, 159-171.

Streib, H., \& Hood, R. W. (2016). Understanding "spirituality": Conceptual considerations. In H. Streib \& R. W. Hood (Eds.), Semantics and psychology of spirituality: A cross-cultural analysis (pp. 3-19). Cham: Springer International.

Stroeken, H. (1983). Psychoanalyse, godsdienst en Boisen. [Psychoanalysis, religion and Boisen]. Kampen: Uitgeverij Kok.

Stroppa, A., \& Moreira-Almeida, A. (2013). Religiosity, mood symptoms and quality of life in bipolar disorder. Bipolar Disorders, 15, 385-393.

Swinton, J., \& Mowat, H. (2006). Practical theology and qualitative research. London: SCM Press.

Troeltsch, E. (1923). Die Soziallehren der christlichen Kirchen und Gruppen [the social teaching of the Christian churches]. In H. Baron (Ed.), Gesammelte Schriften [collected writings] (3rd ed.; Vol. 1). Tübingen: J. C. B. Mohr. https://archive.org/details/gesammelteschrif01 troeuoft.

Van den Berg, A. A. (1988). Als mensen door God worden aangeraakt: Een praktisch-theologische studie over integratie van religieuze ervaring in de kerkelijke gemeente. [When people are touched by God: A practical theological study about the integration of religious experience within the church congregation]. Hooglanderveen: Trepico.

Van der Zwaag, B. (2007). Als Christus Verschijnt: Christusverschijningen in deze tijd. [When Christ appears: Apparitions of Christ today]. Kampen: Uitgeverij Kok.

Van Harskamp, A. (2000). Het nieuw-religieuze verlangen [The new religious longing]. Kampen: Uitgeverij Kok.

Zock, H., Religious voices in the dialogical self: Towards a conceptual-analytical framework on the basis of Hubert Hermans's dialogical self theory (2013). In: M. Buitelaar \& H. Zock, H. (eds.). Religious Voices in Self-Narratives: Making Sense of Life in Times of Transition. Germany: De Gruyter.

Publisher's Note Springer Nature remains neutral with regard to jurisdictional claims in published maps and institutional affiliations.

\section{Affiliations}

\section{Eva Ouwehand ${ }^{1,2} \cdot$ T. Hetty Zock ${ }^{2} \cdot$ J. K. Hanneke Muthert ${ }^{2} \cdot$ Hennie Boeije ${ }^{3}$ Arjan W. Braam $^{4,5}$}

1 Altrecht Expertisegroep Zingeving, Vrijbaan 2, 3705 WC Zeist, The Netherlands

2 Faculty of Theology and Religious Studies, University of Groningen, Groningen, The Netherlands

3 Department of Chronic Illness and Disability, Netherlands Institute for Health Services Research, Utrecht, The Netherlands

4 University of Humanistic Studies, Utrecht, The Netherlands

5 Department of Acute Psychiatry and Department of Residency Training, Altrecht Mental Health Care, Utrecht, The Netherlands 